\title{
Aggressiveness to Pumpkin Cultivars of Isolates of Phytophthora capsici from Pumpkin and Pepper
}

\author{
Byung Kook Lee, Beom Seok Kim, Seog Won Chang, and Byung Kook Hwang, Department of Agricultural \\ Biology, Korea University, Seoul 136-701, Korea
}

\begin{abstract}
Lee, B. K., Kim, B. S., Chang, S. W., and Hwang, B. K. 2001. Aggressiveness to pumpkin cultivars of isolates of Phytophthora capsici from pumpkin and pepper. Plant Dis. 85:497-500.

Nine isolates of Phytophthora capsici obtained from pumpkin and pepper in diverse geographic areas, including Korea, France, Italy, and the United States, were evaluated for their ability to cause disease on nine Korean and Japanese pumpkin cultivars under controlled environmental conditions. No hypersensitive type of resistance was observed in any of the pumpkin cultivars inoculated with $P$. capsici. Disease incidence ranged from low to high, indicating varying levels of partial (quantitative) resistance. In addition, a significant cultivar-isolate interaction was observed, indicating that host specialization was present in some cultivars. Disease severity increased with inoculum density of $P$. capsici. The Korean cultivar Danmatmaetdol was highly resistant to the $P$. capsici isolates tested, suggesting that economic levels of resistance exist in pumpkin. The pumpkin isolates from all locations caused more disease than the pepper isolates to all the pumpkin cultivars tested. Soil-drench and stem-wound inoculation methods were more reliable than a foliar-inoculation method for evaluating pumpkin cultivar resistance.
\end{abstract}

Phytophthora capsici Leonian is a destructive soilborne oomycete pathogen of many cucurbit species $(1,14,16,19)$. Symptoms on cucurbit hosts include dampingoff, foliar blight, stem lesions, fruit rot, and root and crown rot. $P$. capsici causes Phytophthora blight on squash and pumpkin in Korea (7). The incidence of Phytophthora blight on pumpkin (Cucurbita maxima Duchesne) (19) has increased since the 1980s due to the extensive cultivation of pumpkin in the southern areas of Korea (2).

Isolates of $P$. capsici from cucurbits are pathogenic on cucurbits and pepper (11). Ristaino (15) evaluated the relative virulence of cucurbits and pepper isolates of $P$. capsici on pepper and found that all pepper and some cucurbit isolates of $P$. capsici were highly virulent on pepper, whereas other cucurbit isolates were less virulent on pepper. A high level of variation in restriction fragment length polymorphims (RFLPs) was found in isolates of $P$. capsici from Korea, Europe, and New Mexico by examining RFLPs of mitochondrial DNA (3). We also demonstrated differential interactions of $P$. capsici isolates with pepper genotypes at late plant growth stages (5).

$P$. capsici survives in soil as oospores (4), which reach high densities following

Corresponding author: B. K. Hwang
E-mail: bkhwang@korea.ac.kr

Accepted for publication 19 January 2001.

Publication no. D-2001-0312-02R

(C) 2001 The American Phytopathological Society repeated cultivation of pumpkin. The disease is favored by prolonged periods of heavy rainfall from June to August in Korea. Infection by $P$. capsici occurs in the aerial parts of pumpkin plants when zoospores splash from the soil surface during rainfall. Leaves, petioles, fruit, stems, and branches become infected, starting with small, water-soaked lesions. In particular, on the pumpkin fruit, small water-soaked, spherical lesions enlarge to cause severe rotting of the fruit. Whitish gray molds are produced on the infected fruit under humid conditions. Blight symptoms also develop on harvested fruit after they reach market.

The lack of effective measures to reduce soilborne inoculum of $P$. capsici (4) helps explain why epidemics of Phytophthora blight occur frequently in pumpkin-growing areas of Korea. Development of effective management strategies for Phytophthora blight is necessary to sustain acceptable production levels of pumpkins. However, no fungicides are available and acceptable levels of resistance have not been developed for the control of Phytophthora blight in Korea (2).

In the present study, we evaluated the pathogenic variation on pumpkin among pumpkin and pepper isolates of $P$. capsici from diverse geographic origins. Levels of resistance of pumpkin genotypes from Korea and Japan also were examined using different $P$. capsici isolates and inoculation methods under controlled environmental conditions.

\section{MATERIALS AND METHODS}

Plant, pathogen, and inoculum. Four Korean pumpkin cultivars (Danmat- maetdol, Bam, Danbam, and Hukpidan) and five Japanese cultivars (Baekmanamkwa, Evis, Guriniski, Hukorievis, and Hukwang) were used for evaluating cultivar resistance to nine isolates of $P$. capsici. Seeds of each cultivar were sown in plastic pots ( 5 by 15 by $10 \mathrm{~cm}$ ) containing a steamsterilized soil mix of composted soil, loam soil, and sand (1:2:1, vol/vol/vol). Pumpkin plants were raised in a growth room at $25 \pm 2{ }^{\circ} \mathrm{C}$ with 5,000 lx illumination for 16 $\mathrm{h} /$ day.

Nine isolates of P. capsici (P98130, P98131, and P98132 from pumpkin; and 87L19, Yunchun97, S197, War2, CBS 178.26, and Pa94 from pepper) were used to inoculate the nine pumpkin cultivars. The geographic origin, sources, and compatibility types of the nine isolates of $P$. capsici used in this study are described in Table 1. Isolates P98130, P98131, and P98132 were isolated in 1998 from pumpkin plants in Korea. Isolates 87L19, Y97, and $\mathrm{Pa} 94$ were isolated from pepper plants in Korea. The French isolate S197 was supplied by E. Pochard of the Plant Pathology Station, Institut National de la Recherche Agronomique at Montfavet, France. The Italian pepper isolate CBS 178.26 was obtained from the Centraal Bureau voor Schimmelcultures (CBS) at Baarn, The Netherlands. The pepper isolate War2 was obtained from J. B. Ristaino, North Carolina State University.

All isolates were grown on oatmeal agar at $28^{\circ} \mathrm{C}$ for 7 to 10 days and then incubated under fluorescent light at $28^{\circ} \mathrm{C}$ for 2 days to produce sporangia. Sterilized tap water was poured into the plates to harvest sporangia. The sporangial suspension was chilled at $4^{\circ} \mathrm{C}$ for 30 to $60 \mathrm{~min}$ to induce zoospore release and then decanted through four layers of cheesecloth. Zoospore suspension was adjusted to the required concentration with sterilized tap water.

Inoculation procedures and disease evaluation. Pumpkin plants at the two-, four-, and five-leaf stages were inoculated by drenching the soil with zoospore suspensions at a rate of from $10^{3}$ to $10^{6} \mathrm{zoo}-$ spores $/ \mathrm{ml}$. A $10-\mathrm{ml}$ suspension of motile zoospores was poured uniformly over the surface of the soil in each pot. Immediately after soil drenching, pots were placed in a large plastic tray filled with tap water and stored for 2 weeks in the growth room. Disease severity was rated daily after inoculation based on a 0 -to- 5 scale, where 0 = no visible symptoms, 1 = leaves slightly 
wilted with brownish lesions beginning to appear on stems, 2 = stem lesions extending to cotyledons and $30 \%$ of the plant diseased, $3=$ stem lesions extending to petioles and $50 \%$ of the plant diseased, $4=$ petioles collapsed and $80 \%$ of the plant diseased, and $5=$ plant dead.

Plants at the two-, four-, and five-leaf stages also were inoculated using a woundinoculation procedure with zoospore suspensions of $10^{3}$ to $10^{6}$ zoospores $/ \mathrm{ml}$. Pumpkin stems were wounded by making a $1-\mathrm{cm}$ longitudinal slit in the stem $2 \mathrm{~cm}$ above the soil surface, after which a small quantity of sterile cotton soaked in a zoospore suspension was placed on the wound. Inoculation sites were covered with plastic tape to maintain moist conditions favorable for penetration. Disease severity was rated daily after inoculation based on a 0 -to-5 scale, as indicated above.

Plants at the two-, four-, and five-leaf stages also were inoculated using a foliarspray of a zoospore suspension. Zoospore suspensions of $10^{3}$ to $10^{5}$ zoospores $/ \mathrm{ml}$ were sprayed to runoff on the leaves of pumpkin plants. Inoculated plants were placed in a moist chamber at $95 \%$ relative humidity and $28^{\circ} \mathrm{C}$ with fluorescent light for $16 \mathrm{~h}$ a day. The plants were then transferred to the growth room at $80 \pm 10 \%$ humidity and $28^{\circ} \mathrm{C}$ with fluorescent light for $16 \mathrm{~h}$ a day. Disease severity was rated daily after inoculation based on a 0 -to- 5 scale, as indicated above.

Data analysis. Disease severity ratings were used to calculate area under disease progress curves (AUDPCs) using the formula by Shaner and Finney (17): AUDPC $=n \Sigma i=1\left(X_{i+1}+X_{i}\right)\left(t_{i+1}-t_{i}\right) / 2$, where $X_{i}$ $=$ disease severity at the $i$ th observation, $t_{i}$ $=$ days at the $i$ th observation, and $n=$ total number of observations. Analysis of variance (ANOVA) was conducted to determine the effect of cultivar, isolate, and cultivar-isolate interaction. A linear regression of disease severity on the $\log _{10^{-}}$ transformed inoculum concentration of $P$. capsici isolate $\mathrm{S} 197$ was determined using linear regression of Sigmaplot Version 5.0

Table 1. Origins of Phytophthora capsici isolates used in this study

\begin{tabular}{|c|c|c|c|}
\hline Isolate & Origin & Source $^{a}$ & Compatibility type \\
\hline P98130 & Pumpkin, Korea & NIAST & A2 \\
\hline P98131 & Pumpkin, Korea & NIAST & A2 \\
\hline P98132 & Pumpkin, Korea & NIAST & $\mathrm{A} 2$ \\
\hline 87L19 & Pepper, Korea & NIAST & A1 \\
\hline Y97 & Pepper, Korea & KU & A1 \\
\hline Pa94 & Pepper, Korea & KU & A1 \\
\hline S197 & Pepper, France & INRA & A1 \\
\hline CBS 178.26 & Pepper, Italy & CBS & A1 \\
\hline War2 & Pepper, USA & NCSU & A1 \\
\hline
\end{tabular}

${ }^{a}$ NIAST $=$ Plant Pathology Division, National Institute of Agricultural Science and Technology at Suwon, Korea; KU = Department of Agricultural Biology, Korea University at Seoul, Korea; INRA = supplied by E. Pochard, Plant Pathology Station, Institut National de la Recherche Agronomique at Montfavet, France; CBS = Centraalbureau voor Schimmecultures at Baarn, The Netherlands; and $\mathrm{NCSU}=$ Department of Plant Pathology, North Carolina State University at Raleigh.

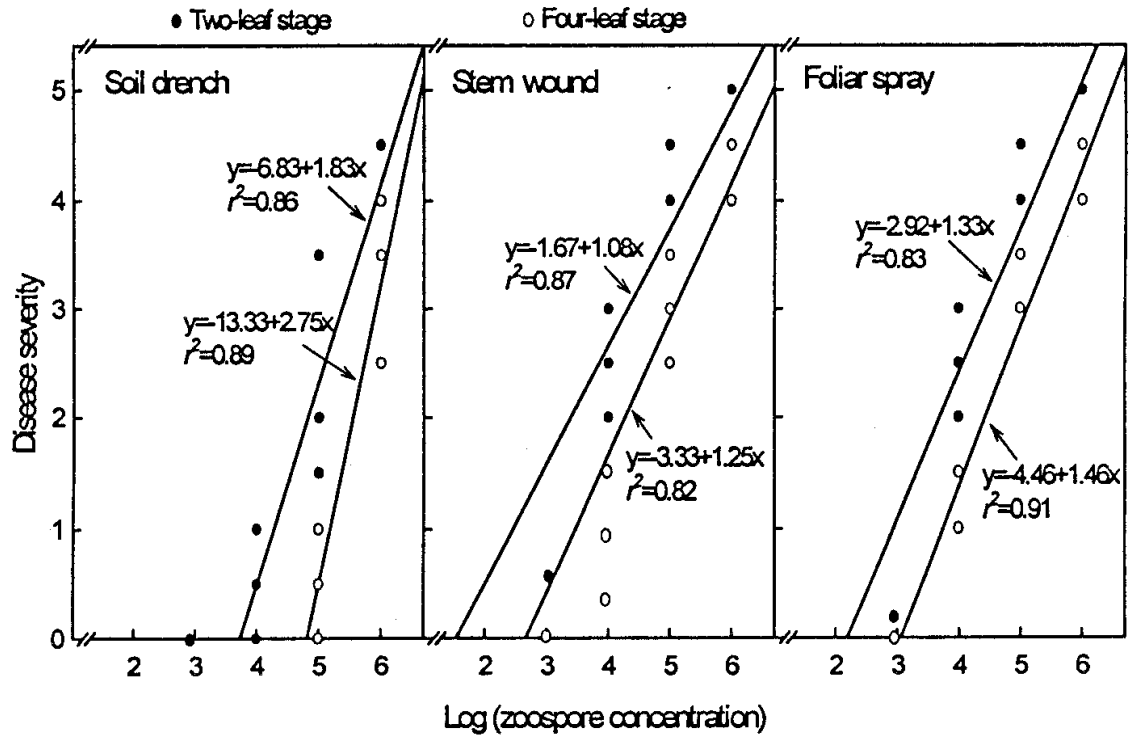

Fig. 1. Effect of inoculum concentration on disease development in pumpkin plants (cv. Bam) inoculated with Phytophthora capsici isolate S197 by different methods at two-and four-leaf stages. Disease severity was rated 14 days after inoculation based on a 0 -to- 5 scale, where $0=$ no visible symptoms and $5=$ plant dead.
Program (San Rafel, CA). All data are the means of six plants inoculated with each of nine isolates. All experiments were performed twice with similar results; data are presented from one experiment only.

\section{RESULTS}

Effect of inoculum concentration of $P$. capsici on disease development in pepper plants was evaluated by soil drench, stemwound, and foliar-spray inoculation at the two- and four-leaf stages (Fig. 1). Disease severity on pumpkin plants (cv. Bam) increased as inoculum density increased from $10^{3}$ to $10^{6}$ zoospores $/ \mathrm{ml}$. A linear relationship was observed between inoculum density and disease severity on pumpkin plants at the two- and four-leaf stages. Few symptoms were induced on pumpkin plants inoculated with $10^{3}$ zoospores $/ \mathrm{ml}$ with the different inoculation techniques. Pumpkin plants were more resistant to $P$. capsici infection at the four-leaf stage than at the two-leaf stage. Disease severity was intermediate (severity ratings of 1 to 3 ) at $10^{4}$ to $10^{5}$ zoospores $/ \mathrm{ml}$ inoculated by soildrench or stem-wound methods at the twoleaf stage. At $10^{6}$ zoospores $/ \mathrm{ml}$, all juvenile plants at the two-leaf stage were killed (severity rating of 4 to 5) within 7 to 10 days after inoculation. With inoculation by foliar spray, slight differences were observed in disease severity between the twoand four-leaf stages.

Varying levels of disease were observed with the nine isolates of $P$. capsici on the nine Korean and Japanese pumpkin cultivars (Table 2). In the stem-wound-inoculated pumpkin plants, $P$. capsici invaded the vascular bundles through the wounds and caused rapidly expanding stem lesions. The stem lesions were initially brown and moist, then later became dry. Leaves of infected plants were wilted as disease became severe. No hypersensitive symptoms were observed in any of the infected plants at the two-leaf stage. The ranks of mean AUDPCs based on disease severity were consistently in the order Hukpidan $>$ Hukwang $>$ Danbam $>$ Hukorievis $>$ Bam $>$ Guriniski > Evis > Baekmanamkwa > Danmatmaetdol for the pumpkin cultivars tested and P98131 > 87L19 > P98130 > P98132 > Y97 > S197 > War2 > Pa94 > CBS 178.26 for the isolates of $P$. capsici tested (Table 2). Significant differences among the cultivars tested were found in resistance to $P$. capsici blight. In particular, the Korean cv. Danmatmaetdol was consistently highly resistant to all the isolates tested, whereas the Japanese cvs. Evis and Guriniski were moderately resistant. The nine isolates of $P$. capsici also exhibited different levels of aggressiveness to the pumpkin cultivars. The pumpkin isolates P98131, P98130, and P98132 caused more disease in the pumpkin cultivars tested than did the pepper isolates Y97, S197, War2, $\mathrm{Pa} 94$, and CBS 178.26. The pepper isolate 87L19 from Korea was an exception. 
The ANOVA of the AUDPCs obtained by the stem-wound inoculation method in this experiment showed highly significant effects of cultivar, isolate, and cultivarisolate interactions on the disease progress on pumpkin plants (Table 3 ). The pumpkin cultivars and the $P$. capsici isolates interacted differentially when the Korean and Japanese cultivars were inoculated with each of pumpkin and pepper isolates.

Hukpidan and Danmatmaetdol, which were the most susceptible and the most resistant among the cultivars tested, respectively, were reevaluated by soildrench, stem-wound, and foliar-spray inoculation at different leaf stages with three isolates that differed in aggressiveness (Table 4). Disease progress on Hukpidan and Danmatmaetdol differed at the twoand five-leaf stages. When inoculated with each of the three isolates using soil-drench and stem-wound techniques, Danmatmaetdol was more resistant to all the isolates tested at both growth stages than Hukpidan, and the pumpkin isolate P98131 was more aggressive to the two pumpkin cultivars than to the two pepper isolates. However, when a foliar-spray inoculation was used, no differences were observed in aggressiveness in the two cultivars. Isolate P98131 was more aggressive to cv. Hukpidan than isolates S197 and CBS 178.26 at the two- and five-leaf stages. The three isolates showed no difference in level of aggressiveness to cv. Danmatmaetdol when inoculated by either method at these leaf stages.

\section{DISCUSSION}

In the present study, aggressiveness of nine isolates of $P$. capsici from pumpkin and pepper of diverse geographic origins, including Korea, France, Italy, and the United States, was evaluated on nine Korean and Japanese pumpkin cultivars under controlled environmental conditions. The differences between the susceptible and resistant responses of pumpkin plants to Phytophthora blight were quantitative rather than qualitative, because no hypersensitive reactions were observed in any of the pumpkin cultivars inoculated with $P$. capsici. The symptoms caused by various isolates developed more slowly on resistant cv. Danmatmaetdol than on the other cultivars tested. The quantitative evaluation of resistance of pepper and tomato cultivars to different isolates of $P$. capsici in earlier studies $(6,8)$ supports the existence of quantitative resistance in pumpkin plants to Phytophthora blight. This finding suggests that the Korean and Japanese pumpkin cultivars tested may not possess resistance genes governing hypersensitive responses to Phytophthora blight. Although significant differences were observed in the cultivar-isolate interactions, there was no indication of single gene resistance to $P$. capsici in the pumpkin cultivars tested.

Inoculum density of $P$. capsici affected development of Phytophthora blight in pumpkin seedlings at the two developmental stages. With a low level of inoculum density $\left(10^{3}\right.$ zoospores $\left./ \mathrm{ml}\right)$, few symptoms appeared on pumpkin seedlings, irrespective of inoculation techniques. Generally, as inoculum density increased, symptom development increased, suggesting that higher inoculum densities may contribute to rapid development of Phytophthora blight.

Pumpkin cultivars became slightly resistant as plants grew older. These results would imply that expression of age-related resistance to Phytophthora blight may not be apparent in pumpkin plants. In recent studies, however, age-related resistance has been demonstrated to be very effective in inhibiting development of Phytophthora blight in pepper and tomato plants at later growth stages $(6,8,9)$.

Significant differences among the isolates tested were shown in aggressiveness to the Korean and Japanese pumpkin cultivars, irrespective of host or country of origin. In general, all the isolates of $P$.

Table 3. Analysis of variance for the areas under disease progress curves (AUDPCs) on nine pumpkin cultivars stem-wound inoculated with nine isolates of Phytophthora capsici

\begin{tabular}{lrccc}
\hline Source of variation & df & Mean square & $\boldsymbol{F}$ value & $P$ \\
\hline Cultivar & 8 & 386.6 & 81.3 & $<0.01$ \\
Isolate & 8 & 565.1 & 118.8 & $<0.01$ \\
Cultivar-isolate & 64 & 16.4 & 3.4 & $<0.01$ \\
\hline
\end{tabular}

Table 4. Areas under disease progress curves (AUDPCs) on two pumpkin cultivars inoculated at different leaf stages with three isolates of Phytophthora capsici using soil-drench, stem-wound, and foliar-spraying methods ${ }^{\mathrm{a}}$

\begin{tabular}{lccccc}
\hline & \multicolumn{2}{c}{ Two-leaf stage } & & \multicolumn{2}{c}{ Five-leaf stage } \\
\cline { 2 - 3 } \cline { 5 - 5 } Method, isolate $^{\mathbf{b}}$ & Hukpidan & Danmatmaetdol & & Hukpidan & Danmatmaetdol \\
\hline Soil-drench & & & & & \\
P98131 & $25.3 \pm 2.1$ & $2.1 \pm 0.9$ & & $20.5 \pm 0.8$ & $0.0 \pm 0.0$ \\
S197 & $16.5 \pm 1.7$ & $0.7 \pm 0.2$ & & $13.5 \pm 0.9$ & $0.3 \pm 0.1$ \\
CBS 178.26 & $16.8 \pm 1.3$ & $0.2 \pm 0.1$ & & $12.5 \pm 0.9$ & $0.0 \pm 0.0$ \\
Stem-wound & $26.2 \pm 2.6$ & $7.3 \pm 4.3$ & & $22.8 \pm 1.8$ & $1.5 \pm 1.3$ \\
P98131 & $19.5 \pm 2.2$ & $6.0 \pm 4.0$ & & $16.5 \pm 1.8$ & $3.3 \pm 0.8$ \\
S197 & $16.2 \pm 1.1$ & $5.5 \pm 4.9$ & & $15.3 \pm 2.3$ & $0.4 \pm 0.2$ \\
CBS 178.26 & & & & \\
Foliar-spray & $35.8 \pm 0.7$ & $31.1 \pm 1.1$ & & $32.4 \pm 0.4$ & $28.9 \pm 0.9$ \\
P98131 & $36.1 \pm 1.5$ & $30.9 \pm 1.3$ & & $29.0 \pm 2.8$ & $27.4 \pm 1.0$ \\
S197 & $35.8 \pm 0.3$ & $28.2 \pm 0.4$ & & $31.0 \pm 1.2$ & $26.5 \pm 1.9$ \\
CBS 178.26 & & & & & \\
\hline
\end{tabular}

a AUDPCs were calculated using a disease severity rating based on a 0 -to-5 scale, where $0=$ no visible symptoms and $5=$ plant dead. All data are means \pm standard deviations from six replicates.

b Isolate P98131 was obtained from pumpkin and isolates S197 and CBS 178.26 were from pepper.

Table 2. Areas under disease progress curves (AUDPCs) on nine pumpkin cultivars at the two-leaf stage in an evaluation of aggressiveness of nine Phytophthora capsici isolates by using the stem-wound inoculation method ${ }^{\mathrm{a}}$

\begin{tabular}{|c|c|c|c|c|c|c|c|c|c|c|}
\hline \multirow[b]{2}{*}{ Isolate } & \multicolumn{10}{|c|}{ AUDPCs on different cultivars } \\
\hline & Danmatmaetdol & Baekmanamkwa & Evis & Guriniski & Bam & Hukorievis & Danbam & Hukwang & Hukpidan & Average \\
\hline P98131 & 11.90 & 14.70 & 13.08 & 15.55 & 14.25 & 16.44 & 16.79 & 16.71 & 13.92 & 14.82 \\
\hline 87L19 & 6.17 & 13.20 & 13.29 & 10.54 & 13.79 & 16.08 & 15.00 & 14.25 & 16.20 & 13.17 \\
\hline P98130 & 4.71 & 11.67 & 11.54 & 15.13 & 11.45 & 11.29 & 14.54 & 12.92 & 15.46 & 12.08 \\
\hline P98132 & 5.08 & 10.79 & 13.65 & 11.05 & 11.35 & 12.25 & 13.00 & 14.46 & 12.70 & 11.59 \\
\hline Y97 & 0.00 & 6.50 & 8.83 & 6.00 & 10.42 & 10.17 & 11.92 & 11.92 & 14.46 & 8.91 \\
\hline S197 & 1.04 & 5.42 & 5.00 & 7.90 & 10.60 & 12.04 & 12.96 & 14.00 & 10.38 & 8.82 \\
\hline WAR2 & 1.75 & 5.50 & 7.00 & 6.81 & 7.25 & 10.71 & 9.92 & 11.63 & 12.75 & 8.15 \\
\hline $\mathrm{Pa} 94$ & 0.54 & 6.46 & 7.17 & 7.33 & 6.33 & 3.00 & 8.04 & 8.85 & 9.17 & 6.32 \\
\hline CBS 178.26 & 0.00 & 3.92 & 1.54 & 4.75 & 3.15 & 6.96 & 5.79 & 4.67 & 6.42 & 4.13 \\
\hline Average & 3.47 & 8.69 & 9.01 & 9.45 & 9.84 & 10.99 & 11.99 & 12.16 & 12.39 & $\ldots$ \\
\hline
\end{tabular}

a AUDPCs were calculated using a disease severity rating based on a 0 -to- 5 scale, where $0=$ no visible symptoms and $5=$ plant dead. Plants at two-leaf stage were inoculated with a zoospore suspension $\left(10^{5} / \mathrm{ml}\right)$ on wounded slits of pumpkin stems $1 \mathrm{~cm}$ from the soil surface. 
capsici from pumpkin plants were pathogenic to all the pumpkin cultivars tested. In particular, pumpkin isolates such as P98130, P98131, and P98132 were found to be more aggressive than the pepper isolates of different geographic origins to all the pumpkin cultivars tested, which suggests that the pumpkin isolates may possess specific virulence factors for interaction of pumpkin as compared with pepper. These findings are well supported by the results of Ristaino (15) that some cucurbit isolates of $P$. capsici caused less disease on pepper than on cucurbits. Interestingly, pepper isolate S197, which showed a high level of virulence on the French and Korean pepper cultivars $(8,12,13)$ or Korean tomato cultivars (6), was moderately aggressive on all the Korean and Japanese pumpkin cultivars tested. However, isolate CBS 178.26, which has been maintained in CBS since isolation in 1926 from Italy, was the most weakly aggressive on the pumpkin cultivars. In our earlier studies, Italian isolate CBS 178.26 exhibited the least aggressiveness to the Korean pepper cultivars (8) but was moderately virulent to the Korean tomato cultivars (6). These facts suggest that, in vitro, long-term maintenance of isolate CBS 178.26 may result in the decrease of virulence on host plants.

Inoculation methods greatly affected the evaluation of pumpkin cultivars for resistance to $P$. capsici infection. Soil-drench and stem-wound inoculation methods could well evaluate pumpkin cultivars for resistance to the Phytophthora disease. However, there were no significant differences in disease severity between susceptible cv. Hukpidan and resistant cv. Danmatmaetdol when the inoculation was by foliar spray (Table 4). These data suggest that foliar inoculation may not be reliable for precisely evaluating cultivar resistance of pumpkin, as previously demonstrated in the pepper- $P$. capsici system $(8,9)$. It should also be noted that the differences between $P$. capsici isolates in aggressiveness were not observed on the inoculated leaves of pumpkins.

The Korean pumpkin cv. Danmatmaetdol showed a high level of resistance to the $P$. capsici isolates tested, suggesting a possible existence of resistance sources in pumpkin. Expression of resistance in this cultivar was more pronounced when inoculated by soil-drench and stem-wound methods rather than by foliar spray. Although inheritance of resistance to $P$. capsici is known to be controlled by two distinct genes in pepper $(10,18)$, there is little information on sources and inheritance of resistance to $P$. capsici in pumpkin. Planting pumpkin cultivars such as Danmatmaetdol, which exhibit resistance to Phytophthora blight, may be desirable for the control of the Phytophthora disease in pumpkin-growing fields.

\section{ACKNOWLEDGMENTS}

We thank H.-T. Lee for advice on the determination of compatibility type of $P$. capsici isolates and H.-J. Jee for providing some isolates of $P$. capsici.

\section{LITERATURE CITED}

1. Café-Filho, A. C., Duniway, J. M., and Davis, R. M. 1995. Effect of the frequency of furrow irrigation on root and fruit rots of squash caused by Phytophthora capsici. Plant Dis. 79:44-48.

2. Cho, Y. D., Kang, S. G., and Chung, J. H. 1997. Cultivars and sowing data for summer season production of sweet pumpkin in Cheju province. RDA. J. Hortic. Sci. 39:33-38.

3. Hwang, B. K., de Cock, A. W. A. M., Bahnweg, G., Prell, H. H., and Heitefuss, R. 1991. Restriction fragment length polymorphisms of mitochondrial DNA among Phytophthora capsici isolates from pepper (Capsicum annuum). Syst. Appl. Microbiol. 14:111-116.

4. Hwang, B. K., and Kim, C. H. 1995. Phytophthora blight of pepper and its control in Korea. Plant Dis. 79:221-227.

5. Hwang, B. K., Kim, Y. J., and Kim, C. H. 1996. Differential interactions of Phytophthora capsici isolates with pepper genotypes at various growth stages. Eur. J. Plant Pathol. 102:311-316.
6. Hwang, J. S., and Hwang, B. K. 1993. Quantitative evaluation of resistance of Korean tomato cultivars to isolates of Phytophthora capsici from different geographic areas. Plant Dis. 77:1256-1259.

7. Hyun, J. S. 1972. A list of plant diseases, insect pests, and weeds in Korea. The Korean Society of Plant Protection, Suweon, Korea.

8. Kim, E. S., and Hwang, B. K. 1992. Virulence to Korean pepper cultivars of isolates of Phytophthora capsici from different geographic areas. Plant Dis. 76:486-489.

9. Kim, Y. J., Hwang, B. K., and Park, K. W. 1989. Expression of age-related resistance in pepper plants infected with Phytophthora capsici. Plant Dis. 73:745-747.

10. Kimble, K. A., and Grogan, R. G. 1960. Resistance to Phytophthora root rot in pepper. Plant Dis. Rep. 44:872-873.

11. Kreutzer, W. A., Bodine, E. W., and Durrell, L. W. 1940. Cucurbit diseases and rot of tomato fruit caused by Phytophthora capsici. Phytopathology 30:972-976.

12. Palloix, A., Daubeze, A. M., and Pochard, E. 1988. Time sequences of root infection and resistance expression in an artificial inoculation method of pepper with Phytophthora capsici. J. Phytopathol. 123:12-24.

13. Palloix, A., Daubeze, A. M., and Pochard, E. 1988. Phytophthora root rot of pepper: Influence of host genotype and pathogen strain on the inoculum density-disease severity relationships. J. Phytopathol. 123:25-35.

14. Polach, F. J., and Webster, R. K. 1972. Identification of strains and inheritance of pathogenicity in Phytophthora capsici. Phytopathology 62:20-26.

15. Ristaino, J. B. 1990. Intraspecific variation among isolates of Phytophthora capsici from pepper and cucurbit fields in North Carolina. Phytopathology 80:1253-1259.

16. Saour, M. M., and Butler, E. E. 1967. A root and crown rot of tomato caused by Phytophthora capsici and P. parasitica.. Phytopathology 57:510-515.

17. Shaner, G., and Finney, R. E. 1977. The effect of nitrogen fertilization on the expression of slow-mildewing resistance in Knox wheat. Phytopathology 67:1051-1056.

18. Smith, P. G., Kimble, K. A., Grogan, R. G., and Millett, A. H. 1967. Inheritance of resistance in peppers to Phytophthora root rot. Phytopathology 57:377-379.

19. Tompkins, C. M., and Tucker, C. M. 1941. Root rot of pepper and pumpkin caused by Phytophthora capsici Leo. J. Agric. Res. 63:417-426. 